\title{
Formation of Comprehensive Service System of Belt Conveyor Gearboxes
}

\author{
Boris Gerike ${ }^{1, *}$, Yuriy Drozdenko ${ }^{1}$, Evgeniy Kuzin ${ }^{2}$, Igor Ananyin ${ }^{3}$, and Dilshad \\ Kuziev $^{4}$ \\ ${ }^{1}$ T.F. Gorbachev Kuzbass State Technical University, Department of Mining Machinery and \\ Complexes, 650000 Vesennaya Str. 28, Kemerovo, Russian Federation \\ ${ }^{2}$ T.F. Gorbachev Kuzbass State Technical University, Prokopyevsk Branch, 653033 Nogradskaya \\ Str. 19a, Prokopyevsk, Russian Federation \\ ${ }^{3}$ JSC "SUEK-Kuzbass", 652507 Vasilyeva Str. 1, Leninsk-Kuznetskiy Russian Federation \\ ${ }^{4}$ National Research Technical University "NITU “MISiS”, 119991, Moscow, 4 Leninsky av., Russian \\ Federation
}

\begin{abstract}
Efficiency improvement of mining equipment, significant qualitative growth of production is impossible without equipment with high operational reliability. Technical level enhancement of mining engineering products is one of the most important tasks associated with the development of reliability and durability of mining equipment. Ensuring trouble-free operation of the mine enterprise substantially depends on reliability of transport equipment. An integrated approach of diagnostics of technical condition of gearboxes of belt conveyors will allow increasing reliability of assessment of the arising defects. In article the example of practical application of the integrated approach of diagnostics of reducers based on vibration, television methods and a method of the analysis of impurity in the greasing liquid is given.
\end{abstract}

\section{Introduction}

Technical diagnostics is one of the effective ways to improve reliability of the operating equipment, taking into account specific conditions and operating modes.

Requirements to technical diagnostics in accordance with the Regulatory Act on Labor Safety-10.0-3.01-90 Safety Standards for Face Shovel, Complexes and Coal Machinery include main provisions as follows:

- mining machines and equipment should contain a subsystem for diagnostic provision, and the control of their condition should be carried out in a safe way by measuring and indicating parameters of electrical, hydraulic and pneumatic systems, lubrication systems, bearing units, and automation systems;

- subsystem of diagnostic provision, as a rule, should include: module of object nondestructive testing of technical condition to detect sudden or parametric failures of mining machines elements and their systems; module to determine developing failures by predicting changes in parameters under control;

\footnotetext{
${ }^{*}$ Corresponding author: gbl.gmik@kuzstu.ru
} 
- continuous and periodic monitoring of technical condition [1].

Depending on wear process mode and operating conditions, machine parts are divided into four groups:

- parts, durability of which is due to abrasive wear;

- parts, durability of which is determined by mechanical wear;

- parts, durability of which depends on fatigue strength of metal.

As per various estimates, the use of modern diagnostic methods provides economic benefits by reducing repair and maintenance cost, unplanned downtime and consumption of spare parts, and energy consumption. Nevertheless, in order to achieve great economic effect, it is necessary to apply comprehensive approach for technical evaluation with a high degree of reliability.

\section{Problem statement}

Any operating mining enterprise is a significant number of the most various equipment, successful performance of which provides performance of operations. Ensuring great rates of preparatory and actual mining works is impossible without use of transport systems of great reliability. Sudden failure of at least one belt conveyor can lead to prolonged downtime of the entire mining enterprise. Therefore, all conveyor equipment must be subjected to control and assessment of its actual technical condition in order to detect emerging defects in timely manner.

The main belt conveyor unit providing traction is a gearbox. Downtime analysis proves that gear failure is $12 \%$ of the total failures, and repair time can be up to several days [2]. Therefore, evaluation of the actual technical condition of a gearbox is an urgent task in ensuring smooth operation of the transport chain.

\section{Research result}

Practice of modern diagnosis method application at domestic and foreign enterprises demonstrates reduction in the cost for maintenance and repair without reducing operational reliability and increasing equipment downtime [3-4].

It is obvious that there is no single method of diagnosis, which with a high degree of reliability evaluates technical condition of the object under assessment. In this regard, to reduce emergency downtime it is necessary to apply a comprehensive approach based on several non-destructive testing methods. Composition of the control methods will depend on the type of equipment, conditions and modes of operation, as well as on the set tasks for diagnostic research.

One of the technical condition evaluation methods for gearboxes of mining equipment is vibration diagnostics. Up to $77 \%$ of possible failures can be detected with the help of vibration analysis methods. However, comprehensive use of vibration diagnostics along with heat monitoring and spectral analysis of lubricants will increase reliability of defect evaluation up to $95 \%$ [5-6].

Comprehensive approach to evaluate technical condition of belt conveyor gearboxes should play a key role not only in the operation, but also at their manufacturing. Analysis of the gearbox technical condition after manufacturing and testing at the factory bench, will allow to identify manufacturing errors and eliminate supply of poor quality products to consumer. Based on data obtained during the factory tests, it is possible to develop automatic control systems under a particular production.

For automation of the product inspection for mining machinery manufactory plants it is rational to apply mask technique. The method is based on registration of controlled parameters in certain frequency ranges. Evaluation of the gear state change is based on results 
of the controlled parameter in a given frequency band, number of which can vary from 6 to 30 [7]. The width of the spectral mask bands (frequency bands) is presented in table 1 [8-10].

Table 1. Frequency Bands of Spectral Masks.

\begin{tabular}{|c|c|l|}
\hline No & Frequency Band & \multicolumn{1}{|c|}{ Description } \\
\hline 1 & $(0.5 \ldots 1,5) \times \mathrm{fr}$ and $(1.5 \ldots 2.5) \times \mathrm{fr}$ & $\begin{array}{l}\text { high-energy spectrum components, imbalance or } \\
\text { misalignment }\end{array}$ \\
\hline 2 & $(7.5 \ldots 15.5) \times \mathrm{fr}$. & $\begin{array}{l}\text { low-energy components accompanying roller } \\
\text { bearing defects }\end{array}$ \\
\hline 3 & $(2.5 \ldots 10.5) \times \mathrm{fr}$ & total hardness of the system \\
\hline 4 & $(3 \ldots 15) \times \mathrm{fr}$ & gearing defects \\
\hline 5 & $(15 \ldots 40) \times \mathrm{fr}$ & abrasive wear of gear pairs \\
\hline 6 & $40 * \mathrm{fr}$ & lubrication system malfunction \\
\hline 7 & $(0.1 \ldots 0.9) \times \mathrm{fr}$ & oil wedge defects for sliding bearings \\
\hline 8 & $(\mathrm{n} \pm 1) \times \mathrm{fr}$ & coupling joints damage \\
\hline
\end{tabular}

Comprehensive approach to evaluation of the belt conveyor gear technical condition was tested under industrial conditions during inspection of transport chain at TaldinskayaZapadnaya mine, JSC SUEK-Kuzbass. This paper presents results of Moventas Santasalo D3RST82XO gearboxes monitoring (legend P1 P2...... P9) 3LL-1600 belt conveyor, according to vibration analysis, thermal monitoring and analysis of lubricants. It should be noted that the R3, R4, R5 gearboxes are installed permanently on surface in relatively clean and dry environment, and the R7, R8, R9 gearboxes are installed in conveyor shafts and have been rewired repeatedly.

In tables 2 and 3 there are the spectral analysis results of the mechanical additives content of the least loaded P3 gear and the most loaded P7 gear.

Table. 2. Results of monitoring of the wear products accumulation in oil due to operational life, gr/t for R3 gearbox.

\begin{tabular}{|c|c|c|c|c|c|c|c|c|c|}
\hline Elements & Base-line & 15.03 .13 & 15.04 .14 & 18.09.14 & 04.12.14 & 17.06 .15 & 20.10 .15 & 13.04 .17 & 10.10 .17 \\
\hline \multicolumn{2}{|c|}{ Operational life } & 0 & 9720 & 13248 & 15096 & 19776 & 22776 & 35760 & 40080 \\
\hline $\mathrm{Fe}$ & 200 & 4.695 & 40.98 & 95.17 & 78.02 & 39.15 & 42.57 & 56.11 & 114 \\
\hline $\mathrm{Si}$ & 30 & 11.72 & 33.41 & 35.19 & 41.48 & 37.02 & 38.92 & 35.73 & 39.1 \\
\hline $\mathrm{Cu}$ & 150 & 2.92 & 12.48 & 7.03 & 0.32 & 6.47 & 9.41 & 0.45 & 11.2 \\
\hline $\mathrm{Al}$ & 7 & 0.0678 & 1.48 & 1.41 & 1.84 & 1.44 & 1.53 & 2.61 & 3.12 \\
\hline $\mathrm{Cr}$ & 5 & 0.1733 & 1.24 & 1.08 & 1.56 & 0.79 & 1.09 & 1.23 & 2.47 \\
\hline $\mathrm{Pb}$ & - & 0 & 1.71 & 0.43 & 1.99 & 3.24 & 1.8 & 8.67 & 9.19 \\
\hline $\mathrm{Sn}$ & - & 0 & 1.55 & 6.88 & 6.95 & 4.79 & 8.18 & 7.19 & 6.32 \\
\hline
\end{tabular}

Table 3. Results of monitoring of the wear products accumulation in oil due to operational life, gr/t for P7 gearbox.

\begin{tabular}{|c|c|c|c|c|c|c|c|c|c|}
\hline Elements & Base-line & 22.03.13 & 15.04 .14 & 15.05 .14 & 18.09 .14 & 04.12 .14 & 07.06.16 & 13.04.17 & 10.10 .17 \\
\hline \multicolumn{2}{|c|}{ Operational life } & 0 & 9336 & 10056 & 13080 & 14928 & 19608 & 35592 & 39912 \\
\hline $\mathrm{Fe}$ & 200 & 10.6 & 114 & 120 & 91.8 & 203 & 224 & 1067 & 1073 \\
\hline
\end{tabular}




\begin{tabular}{|c|c|c|c|c|c|c|c|c|c|}
\hline $\mathrm{Si}$ & 30 & 13.1 & 46.8 & 47.1 & 37.1 & 44.5 & 45.8 & 71.3 & 73.2 \\
\hline $\mathrm{Cu}$ & 150 & 1.59 & 5.01 & 6.71 & 7.66 & 0.183 & 9.84 & 0.017 & 14.1 \\
\hline $\mathrm{Al}$ & 7 & 0.0139 & 1.82 & 2.33 & 1.54 & 1.84 & 4.49 & 27.5 & 29.5 \\
\hline $\mathrm{Cr}$ & 5 & 0.337 & 1.29 & 2.35 & 1.11 & 1.55 & 2.59 & 14.05 & 15.4 \\
\hline $\mathrm{Pb}$ & - & 0 & 2.36 & 3.89 & 3.24 & 3.95 & 7.24 & 2.05 & 6.08 \\
\hline $\mathrm{Sn}$ & - & 0 & 6.57 & 6.26 & 6.38 & 8.76 & 8.05 & 25.87 & 27.5 \\
\hline
\end{tabular}

There are graphical results of monitoring of iron, silica and copper accumulation in Fig. $1-3$.

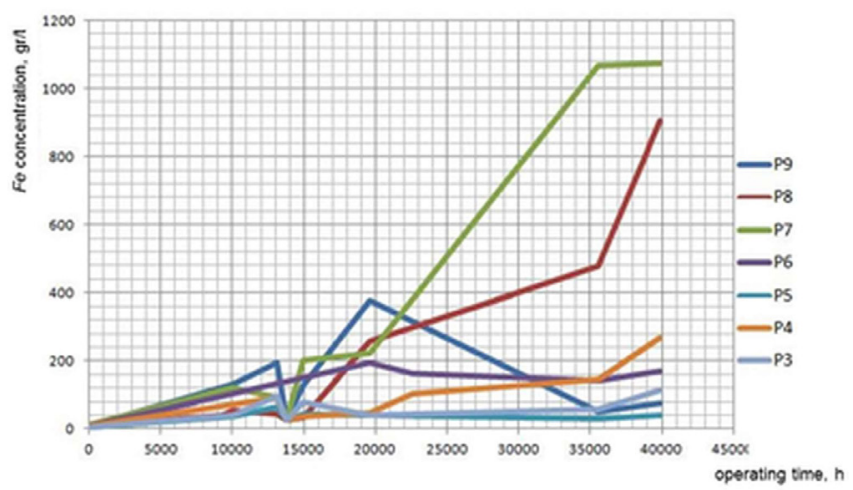

Fig. 1. Results of iron accumulation in oil due to operational life.

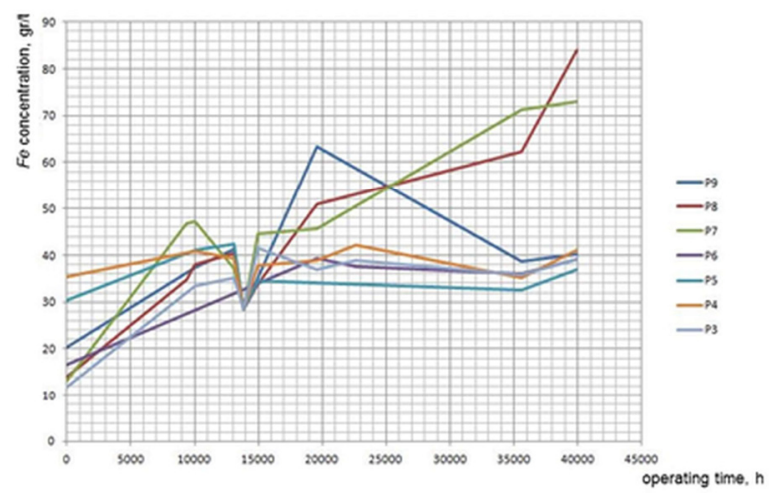

Fig. 2. Results of silica accumulation in oil due to operational life.

The analysis results show that the greatest degradation of oil parameters takes place in P7, P8, P9 gearboxes, and at the same time in R9 gearbox oil has veen changed, and in P7 and P8 gearboxes has not. R3-R5 gearboxes are loaded less and, accordingly, oil degradation occurs later.

Thus, change of lubricating oil in certain intervals, without regard of machine load and operating conditions leads to both a premature change of the still conditioned oil, as well as work on the oil with lost properties. Results of monitoring (see Fig.1-3) confirm the fact that the high silica content, usually caused by dust in gearbox, leads to abrasive wear of the bearing material and gear pairs. 


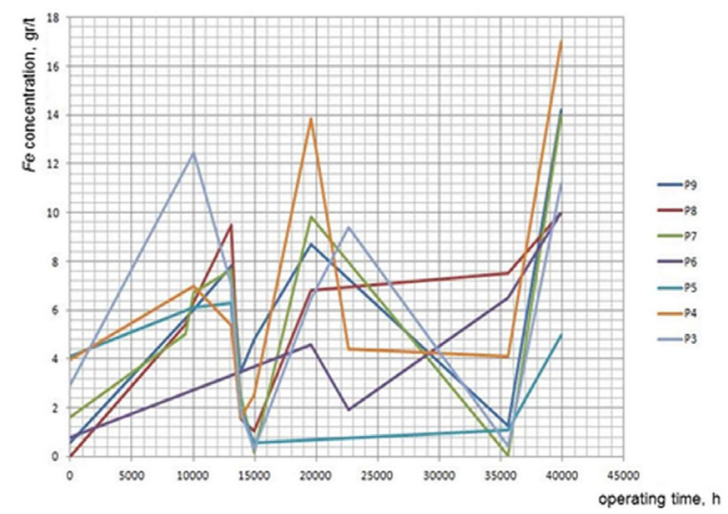

Fig. 3. Results of copper accumulation in oil due to operational life.

Thermal charts of P1 drive in Figure 2 shows gearbox thermal monitor, and thermal charts of $\mathrm{P} 2$ drive is Figure 3.

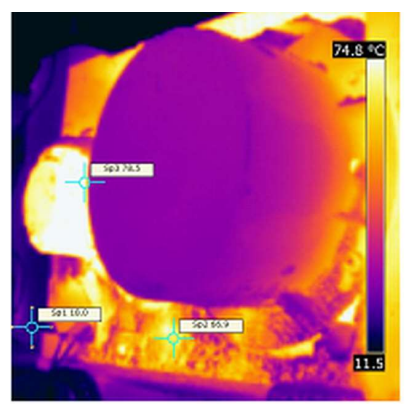

24.08 .2016

Fig. 4. P1 Gearbox Thermal Chart.

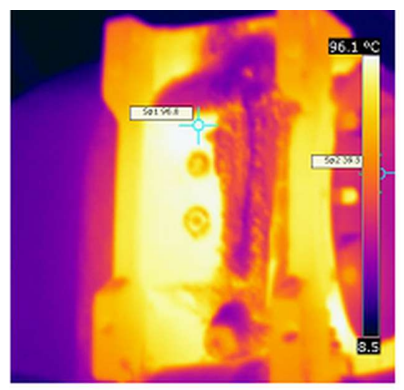

24.08 .16

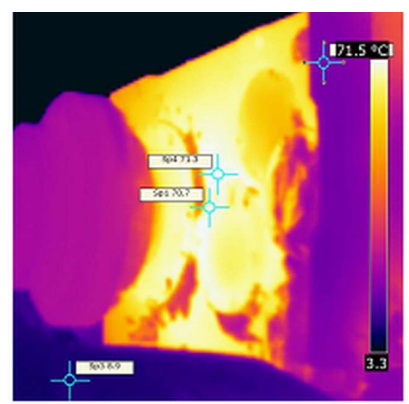

13.04 .2017

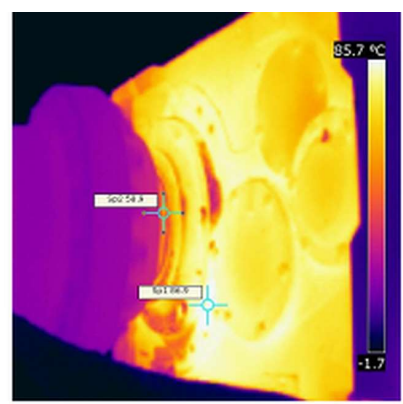

10.10.2017

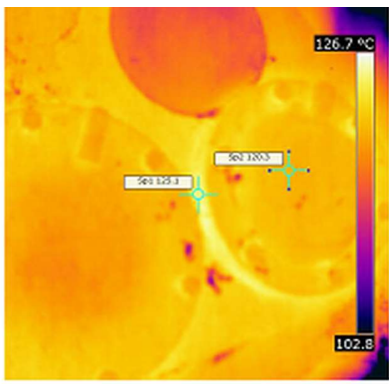

13.04 .17

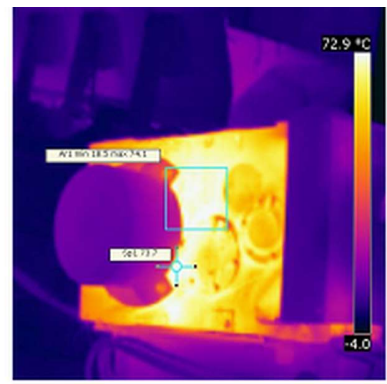

10.10.2017

Fig. 5. P2 Gearbox Thermal Chart.

Permissible oil temperature for gearboxes according to the operating manual is $\mathrm{Tp}$. $\max =121^{\circ} \mathrm{C}$, the gearbox surface temperature is lower at least on 15 degrees and is determined by the formula

$$
T_{p . a c t u a l}+T_{\text {oкp } \text { max }}-T_{\text {env/actual }}<T_{p, \text { max }}-15^{\circ} \mathrm{C}
$$


where, $T_{\text {p.actual }},{ }^{\circ} \mathrm{C}$ - actual gearbox surface temperature; $T_{\text {env, } \max }=35^{\circ} \mathrm{C}$ - maximum permissible environment temperature;

Actual environment temperature on the moment of measurement 24.08.16 $T_{\text {env..actual }}=17 \mathrm{C}, 13.04 .17-T_{\text {env.actual }}=8 \mathrm{C}, 10.10 .17-T_{\text {env.actual }}=4^{\circ} \mathrm{C}$.

Permissible surface gearbox temperature should not be greater $106^{\circ} \mathrm{C}$.

Table 3. Results of R1 Gearbox Thermal Monitor.

\begin{tabular}{|l|c|c|c|c|c|c|}
\hline \multirow{1}{*}{$\begin{array}{c}\text { Name of } \\
\text { unit }\end{array}$} & \multicolumn{2}{|c|}{$\mathbf{2 4 . 0 8 . 1 6}$} & \multicolumn{2}{c|}{$\mathbf{1 3 . 0 4 . 1 7}$} & \multicolumn{2}{c|}{$\mathbf{1 0 . 1 0 . 1 7}$} \\
\cline { 2 - 7 } & $\begin{array}{c}\text { Actual } \\
\text { surface } \\
\text { temperature, } \\
{ }^{\circ} \mathbf{C}\end{array}$ & $\begin{array}{c}\text { Actual } \\
\text { lubricant } \\
\text { temperature, } \\
{ }^{\circ} \mathbf{C}\end{array}$ & $\begin{array}{c}\text { Actual } \\
\text { surface } \\
\text { temperature, } \\
{ }^{\circ} \mathbf{C}\end{array}$ & $\begin{array}{c}\text { Actual } \\
\text { lubricant } \\
\text { temperature, } \\
{ }^{\circ} \mathbf{C}\end{array}$ & $\begin{array}{c}\text { Actual } \\
\text { surface } \\
\text { temperature, } \\
{ }^{\circ} \mathbf{C}\end{array}$ & $\begin{array}{c}\text { Actual } \\
\text { lubricant } \\
\text { temperature, } \\
{ }^{\circ} \mathbf{C}\end{array}$ \\
\hline P1 gearbox & 79.7 & 97.7 & 84,7 & 111.7 & 86.9 & 117.9 \\
\hline P2 gearbox & 96 & 114 & 126 & 153 & 74.1 & 105.1 \\
\hline $\begin{array}{l}\text { Temperature } \\
\text { anomaly, } \\
\Delta T,{ }^{\circ} \mathrm{C}\end{array}$ & \multicolumn{2}{|c|}{16.3} & \multicolumn{2}{|c|}{41.3} & & \\
\hline
\end{tabular}

There are evaluation criteria based on the results of thermal monitor in Table 2 .

Table 4. Evaluation Criteria Based on the Thermal Monitor Results.

\begin{tabular}{|c|c|l|}
\hline $\begin{array}{c}\text { Temperature } \\
\text { Anomaly, } \boldsymbol{\Delta} \boldsymbol{T},{ }^{\circ} \mathbf{C}\end{array}$ & $\begin{array}{c}\text { Actual lubricant } \\
\text { temperature, }{ }^{\circ} \mathbf{C}\end{array}$ & \multicolumn{1}{c|}{ Evaluation Criteria } \\
\hline $5-10$ & $80-90$ & $\begin{array}{l}\text { Category B - limited workability, additional } \\
\text { diagnosis is required }\end{array}$ \\
\hline $10-15$ & $90-100$ & $\begin{array}{l}\text { Category C - critical condition, emergency repair and } \\
\text { additional diagnostics are required }\end{array}$ \\
\hline 15 & $100-110$ & $\begin{array}{l}\text { Category D - unacceptable condition, possible } \\
\text { accident, emergency repair is required, repair is } \\
\text { possible. }\end{array}$ \\
\hline
\end{tabular}

Analysis of the thermal monitor results shows that the temperature of the lubricating oil in gear after repair of the P2 gearbox differs on 12.8 degrees, i.e. corresponds to critical condition, the P1gearbox might soon need to be repaired;

There are result of vibration inspection of the R1, P2 and P3 gearboxes in Figure 6.
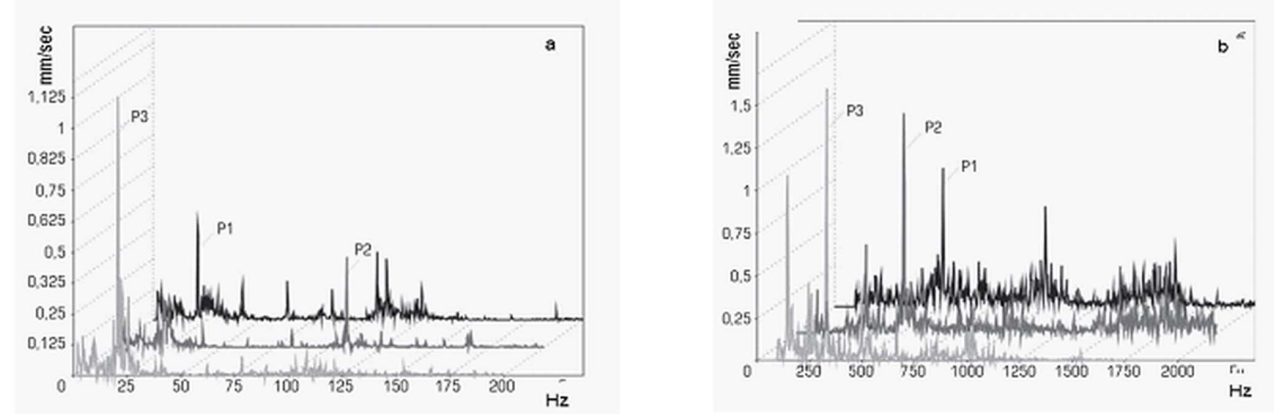

Fig. 6. Comparison of Vibration Spectra in Low-Frequency as of 2-200 Hz (a) and MediumFrequency as of $200-2000 \mathrm{~Hz}$ (b) Bands. 
General level of vibration characterizes technical condition of the $\mathrm{P} 1$ drive as a satisfactory [11-12], technical condition of the P2 drive is estimated as an acceptable (as per general level of vibration, high housing temperature and low oil operating viscosity). At the same time, the normalized oil viscosity value is the greatest in the P2 gearbox that indicates evaporation of easily boiling fractions.

\section{Conclusion}

Based on the vibration parameters monitoring results, emission-spectral analysis of oil and TV control of the bearing support units, it is possible to outline pattern of changes in the gearbox state depending on velocity, load, operating modes and place in the technological chain.

The proposed approach extends capabilities of the diagnostic methods at reliability enhancement of the technical condition evaluation of the gearboxes for mining equipment. Furthermore, it allows to create a regulatory and methodological framework for construction of degradation models of gearbox technical condition, using a significant amount of statistical information regarding defects development.

\section{References}

1. A. A. Puchalski, Mechanical Systems and Signal Processing, 56, 173 (2015)

2. A. Rana, Journal of Quality in Maintenance Engineering, 22(2), 180 (2016)

3. A. E. Sushko, Vibration of machines: measurement of the protection decrease, 4, 24 (2007)

4. A. E. Sushko, Repair. Recovery. Modernization, 8, 5 (2010)

5. G. S. Kelly, Advanced Vibration Analysis (CRC Press, Amsterdam, 2013)

6. P. B. Gerik, V. Y. Blumenstein, Bulletin of the Kuzbass State Technical University, 6, 89 (2016)

7. V. A. Kovalev, A. A. Khoreshok, B. L. Gerike, A. A. Meshkov, Coal in the 21st Century: Mining, Processing and Safety: the 8th Russian-Chinese Symposium, 291 (2016)

8. X. L. Rudlo, M. Arghir, O. Bonneau, S. Guingo, G. Chemla, Journal of Engineering for Gas Turbines and Power, 134:8, 082503 (2012)

9. S. Ierace, S. Cavalieri, Management and Production Engineering Review, 4:2, 37 (2013)

10. N. N. Ishin, A. M. Goman, A. S. Skorokhodov, non-destructive testing and diagnostics, 2:3 (2017)

11. N. N. Ishin, Dynamics and vibration monitoring of gears (Science, Moscow, 2013)

12. A. A. Khoreshok, L. E. Mametyev, A. M. Tsekhin, A. Yu. Borisov, Journal of Mining and Geotechnical Engineering, 1, 64-80 ( 2018) DOI: 10.26730/2618-7434-2018-1-6480 